\title{
Parameters of DC high-speed circuit-breakers
}

\author{
Artur Rojek ${ }^{1, *}$ \\ ${ }^{1}$ Railway Research Institute, ul. Chłopickiego 50, 04-275, Warsaw, Poland
}

\begin{abstract}
DC high-speed circuit-breakers (HSCB) are the basic protection to cut off short-circuit and overload currents. People's and railway infrastructure devices' safety depend on their reliability and parameters. High-speed circuit-breakers, like any other electrical devices, display several electrical and mechanical characteristic parameters, which in many cases are interconnected. The article features these parameters of DC high-speed circuit-breakers that affect the operation safety of electric traction power supply systems. Moreover, it presents ways of their determination basing on laboratory and operational tests. Furthermore, requirements to be met directly and indirectly by DC high-speed circuit-breakers imposed by legal and standardization documents are described. Correlations between the breakers' construction and their parameters are outlined. Basing on tests of leading European producers' breakers, the article presents the impact of parameters of circuit where they are tested as regards HSCB parameters. It also deals with the problem of coordination of short-circuit protection and breaking currents of low values with respect to high-speed circuit-breakers used in Poland.
\end{abstract}

\section{Introduction}

High-speed circuit-breakers sorted in traction substations are subject to several requirements regarding their electrical and mechanical parameters as well as their durability and reliability. The malfunctioning of the circuit-breakers may cause railway infrastructure damage or failure, rail traffic disruptions and in extreme cases may even endanger human health or life.

Prior to high-speed circuit-breakers placing into operation, they undergo numerous examinations and laboratory tests. The basic documents relating to high speed circuit-breakers are EN 50123-1 [3] and EN 50123-2 [4] standards for breakers intended for traction substations and sectioning locations (cabins) as well as EN 60077-3 [8] standard, whose provisions need to be read together with EN 60077-1 [6] and EN 60077-2 [7] standards, defining rolling stock breakers' requirements and tests.

Many provisions of these standards are general and permit a large range of parameters. Consequently, this results in the fact that the interpretation of standard provisions and test results is not unambiguous. It is the target operator who decides what type of breaker to be used in a particular application. Nevertheless, laboratory test results do not always translate directly into HSCB parameters in operation. The scope of tests and related issues are described in [13].

\section{Breaking off short-circuit currents}

High-speed circuit-breakers reducing short-circuit current are used in traction substations and sectioning locations (cabins). They should also be installed in traction units. It means that cutting off the current should take place before it reaches maximum value which depending on the character of short-circuit current flow is a fixed or peak value.

Figures 1 and 2 present short-circuit current flows of different characters and cut off current flows switched off by HSCB. The values shown in the pictures, according to EN 50123-1 [3] standard mean:

- $I_{S S}$ - prospective sustained short circuit current;

- $\hat{I}_{S S}-$ peak of $I_{S S}$;

- $I_{\text {cut off }}-$ cut off current;

- $t_{c}$ - time-constant of the circuit.

Establishing the time-constant of the short-circuit current $t_{c}$ in the way described by EN 50123-1 [3] standard is possible only when the short-circuit current reaches its value determined exponentially, as presented in Fig. 1. In case when the short-circuit current flows as presented in Fig. 2, establishing the time constant of the circuit is not possible. The set short-circuit current $I_{S S}$ in Fig. 1 and Fig. 2 has a similar value. However, the steepness of its rise is definitely different.

\footnotetext{
* Corresponding author: arojek@ikolej.pl
} 


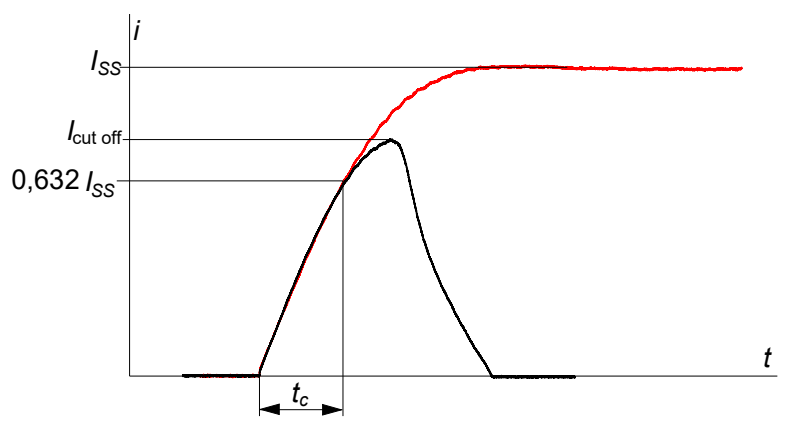

Fig. 1. Short-circuit current oscillogram prior to reaching the sustained value (red) and cut off by HSCB (black) ${ }^{1}$.

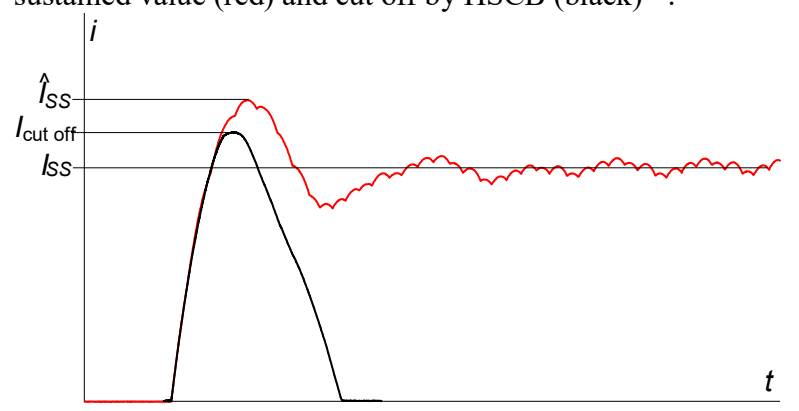

Fig. 2. Short-circuit current flow of value higher than the sustained value (red) and cut off by HSCB (black).

In the event of short circuit on HSCB tripping circuit, the increasing current causes triggering of the breaker when the current value exceeds the level of the trigger setting. Triggering of the breaker should result in its immediate process of limiting and cutting off the current. The opening time $t_{i}$ of currently operating HSCBs and the level of cut off current $I_{\text {cut off }}$ depend on the steepness of short-circuit current rise and the peak value, regardless if it flows exponentially or as presented in Fig. 2.

Due to the fact that the short-circuit current flow has a different character, the provision in Clause 11 of EN 50388 standard [5], which is cited in TSI Energy [1] and TSI Loc\&Pas [2], seems problematic. This point stipulates that breaking capacity of the circuit breaker in the $3 \mathrm{kV}$ DC system should amount $50 \mathrm{kA}$ of the sustained short circuit current $I_{S S}$. As HSCB operation should be fast enough to limit the current value as much as possible, a fortiori, to avoid its setting, without specifying the current peak value, the provision in Clause 11 of EN 50388 standard [5] is not precise enough and does not include all possible cases. A provision stating short- circuit current maximum values and the steepness of its rise would be more precise.

On the basis of the above, in order to define HSCB parameters, maximum value of cut off current and its maximum steepness of rise should be provided.

1 If not marked differently, figures of recorded measurement data were elaborated for the need of this article during tests of HSCB and DC switchgears carried out for Polish or foreign producers.

\section{HSCB characteristics}

High-speed circuit-breakers intended for operation in traction substations and section cabins are divided, inter alia, due to the speed of their operation and short-circuit current limiting. EN 50123-1 standard [3] (points 3.4.7 and 3.4.8) defines three HSCB types: H, V and S. H type breakers are being currently used in railway supply equipment. According to the standard, HSCB type $\mathrm{H}$ should prevent reaching the peak value by short-circuit current, the opening time $t_{i}$ of no more than $5 \mathrm{~ms}$, the total break time $t_{b}$ should not exceed $20 \mathrm{~ms}$ when the value of expected sustained current is at least 7 times higher than the level of the trigger setting and the initial steepness of current has a minimum value of $5 \mathrm{kA} / \mathrm{ms}$.

HSCB characteristics is defined while examining the breaking capacity of maximum short-circuit currents (e.g. duty f). In EN 50123-2 [4] standard, point 5.3.4.2 Table 2, it is defined the tests should be carried out for the time constant resulting from the circuit parameters, however, point 8.3.8.8 in Table 5 stipulates that time constant $t_{c}=0$. Meeting this condition is not possible as there always appears inductance in real circuits, thus $t_{c}>0$. Moreover, EN 50123-2 standard [4] (Table 5) cites provisions of points 3.4.7 and 3.4.8 of EN 50123-1 standard [3], where conditions regarding time constant are not given, only the steepness of short-circuit current rise is stipulated.

Taking into consideration provisions relating to test parameters for HSCB type $\mathrm{H}$ included in the EN 50123-1 [4] and EN 50123-2 [4] standards, the test of maximum currents switching capacity can be carried out in circuits of different parameters, e.g. $\mathrm{d} i / \mathrm{d} t=9,5 \mathrm{kA} / \mathrm{ms}$ or $\mathrm{d} i / \mathrm{d} t=5,1 \mathrm{kA} / \mathrm{ms}$. Both values of steepness rise meet the standard provisions - they are bigger than $5 \mathrm{kA} / \mathrm{ms}$, however, the test results are different, which is illustrated in Fig. 3 and 4. Oscillograms presented in these figures were recorded during the short-circuit test of the same HSCB type. Values of prospective sustained short circuit current $I_{S S}$ were similar. The tests were conducted in different circuits - one in the short-circuit laboratory in the circuit without a reactor and the second in the traction substation with the resultant inductance value of reactors $0,8 \mathrm{mH}$.
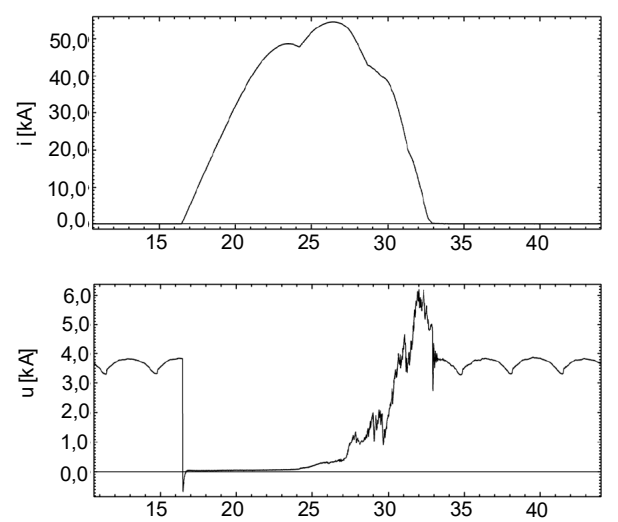

Fig. 3. Short-circuit current and HSCB voltage oscillogram at $\mathrm{d} i / \mathrm{d} t=9,5 \mathrm{kA} / \mathrm{ms} ; t_{b}=15,6 \mathrm{~ms}$, arc energy $401 \mathrm{~kJ}[14]$. 


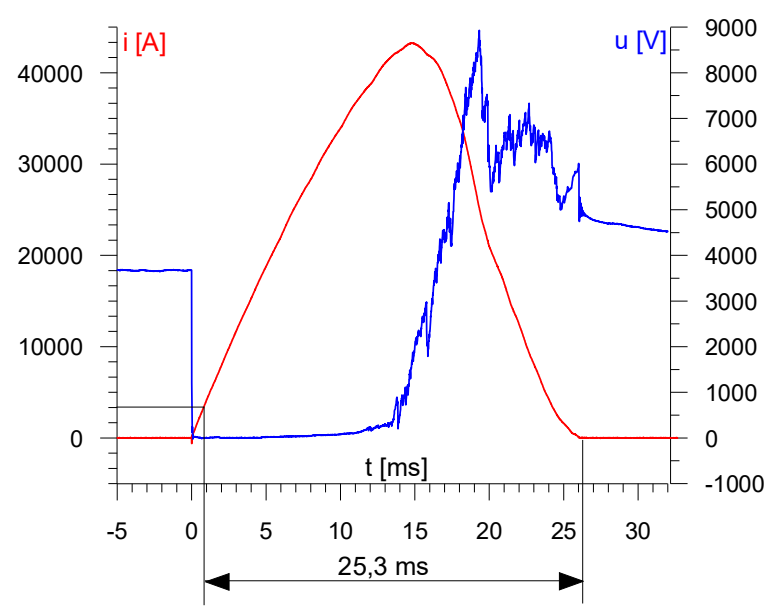

Fig. 4. Short-circuit current and HSCB voltage oscillogram at $\mathrm{d} i / \mathrm{d} t=5,1 \mathrm{kA} / \mathrm{ms} ; t_{b}=25,3 \mathrm{~ms}$, arc energy $1268 \mathrm{~kJ}$.

The total break time $t_{b}$ is the sum of opening time $t_{i}$ and arcing time $t_{a}$. The values of these times depend on the steepness of current changes [11], which result from the parameters of HSCB circuit and construction. In the above-mentioned example, the construction of the breaker did not affect the results (the test were conducted for the same HSCB type) but only the circuit parameters.

Despite the fact that both measurement circuits met the requirements of EN50123-1 [3] and EN 50123-2 [4] standards, the test carried out at $\mathrm{d} i / \mathrm{d} t=9,5 \mathrm{kA} / \mathrm{ms}$ confirmed that examined HSCB fulfills the requirements for type $\mathrm{H}$ breakers, however, at $\mathrm{d} i / \mathrm{d} t=5,1 \mathrm{kA} / \mathrm{ms}$ the total break time $t_{b}$ is too long. Moreover, attention should be paid to the arc energy value whose most energy must be absorbed by arc chute and arc voltage value. In the event of a circuit with a reactor (Fig. 4), the arc energy is over three times bigger than for the circuit without the reactor (Fig.3) and the arc voltage is approx. $50 \%$ bigger.

The above-mentioned example shows that the parameters of HSCB, which positively underwent laboratory tests in a circuit allowing high steepness of current changes, may not be met in a traction substation real circuit. Stating that $\mathrm{HSCB}$ has $\mathrm{H}, \mathrm{S}$ or V characteristics without defining the steepness of shortcircuit current rise is not sufficient for the future user of the breaker.

\section{Breaking times}

The previous point dealt with the impact of the circuit parameters on the time of cutting off the current by HSCB. This time is also dependent on HSCB parameters, including operating time $t_{\mathrm{i}}$ and arc time $t_{a}$.

The operating time largely depends on HSCB construction - the way of its release and contacts opening mechanisms. The arc time also depends on HSCB construction. Its time depends on contacts construction, arc chamber parameters, the arc extinguishing method, magnetic blowout method.

After opening of the breaker's contacts, the arc ignition between them takes place. This arc is short and has a large diameter which causes that its voltage is low. This arc moves to the arc chamber where it significantly lengthens, its diameter decreases and deionization takes place. Since the contacts opening to the moment of arc entering the arc chamber, the arc voltage is low, it does not exceed $10 \%$ of voltage source. Such a low arc voltage practically does not cause any short-circuit current limiting. The time when the low voltage arc occurs is defined as contact arc time $t_{s}$ [15]. EN 50123-1 [3], EN 50123-2 [4] and EN 60077-3 [8] standards do not characterize and do not cover this parameter, despite the fact that it is an essential factor affecting the speed of cutting off the current and the level of its limiting.

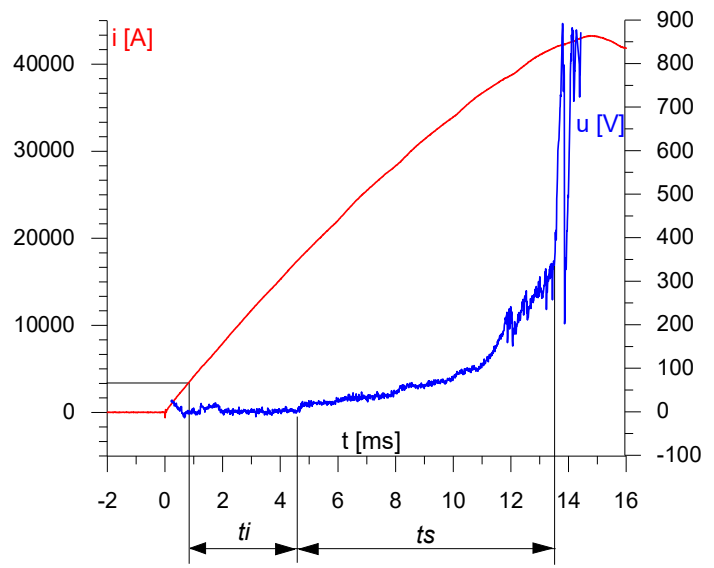

a): $t_{i}=3,3 \mathrm{~ms} ; t_{s}=8,9 \mathrm{~ms} ; I_{\text {cut off }}=43,2 \mathrm{kA}, t_{b}=26 \mathrm{~ms}$

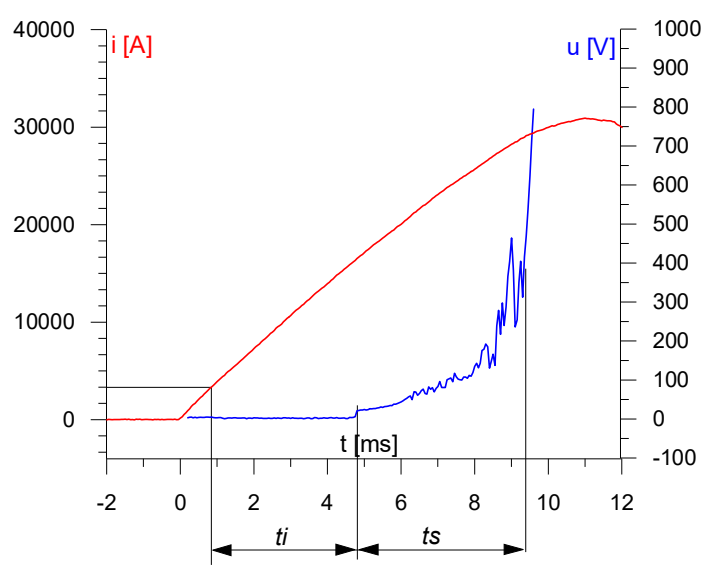

b): $t_{i}=3,4 \mathrm{~ms} ; t_{s}=4,5 \mathrm{~ms} ; I_{\text {cut off }}=30,9 \mathrm{kA}, t_{b}=23 \mathrm{~ms}$

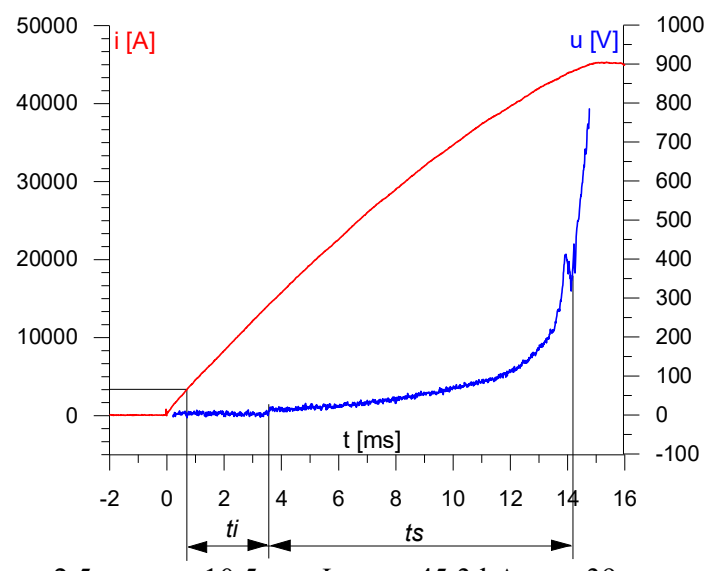

c): $t_{i}=2,5 \mathrm{~ms} ; t_{s}=10,5 \mathrm{~ms} ; I_{\text {cut off }}=45,3 \mathrm{kA}, t_{b}=39 \mathrm{~ms}$

Fig. 5. Short-circuit current and voltage oscillogram, opening time and arc contact time for 3 HSCB types. 
Figure 5 presents the oscillogram of short-circuit current and voltage on three types of HSCB terminals. All flows were recorded during the tests on the same short-circuit and tested breakers had the same levels of setting. The breakers differed in the construction of main contacts and arcing contacts, arc chamber construction and electromagnetic blowout systems.

The analysis of oscillogram presented in Fig. 5 shows that the contact arc time is longer than operating time $t_{i}$. During the $t_{s}$, the current is still rising. The breaker, whose oscillogram are presented in Fig.5c), despite the shortest opening time has the longest $t_{s}$ time, consequently, the longest time of short-circuit breaking and the highest value of cut off current. This breaker has a gap between the main contacts and arcing contacts, the biggest geometrical dimensions of arcing horns, and its arc chamber does not contain electric conductive elements. This results in the fact that the time needed for the arc to relocate from opened contacts inside the arc chamber is the longest.

The breaker which is characterized by the shortest $t_{s}$ time and the lowest $I_{\text {cut off }}$ current (Fig. 5b) has a compact construction of main and arcing contacts, short arcing horns and is equipped with highly efficient magnetic blowout system.

The parameters discussed in this point have a crucial influence on the coordination of short-circuit protections in the vehicle - substation setting, what indirectly affects the reliability of the railway traffic [9]. In order to provide the biggest coordination, the rolling stock breaker should limit the short-circuit current to the lowest level in shortest time. It means that apart from the opening time, also the contact arc time should possible have low values. The bigger the steepness of shortcircuit current rise the higher demands relating to $t_{i}$ and $t_{s}$ times are placed for rolling stock breakers.

Selecting breakers taking into account only their opening time does not guarantee the protection coordination. In case of long $t_{s}$ times, the short-circuit current is able to rise to the value when the traction substation's breaker is released. In the protection coordination there is no correlation between requirements placed for substation and rolling stock HSCB. EN 50123-2 [4] and EN 60077-3 [8] standards are not connected which may cause problems while selecting HSCB parameters.

\section{Critical currents}

Cutting off small currents, called critical currents is a difficult task for HSCBs. Low value of current flowing through magnetic blowout systems results in low value of magnetic field affecting the arc in order of its relocation to the arc chamber, lengthening and extinguishing. Consequently, there are long arc times occurring during critical currents cutting off. The arc time rises then the cutting off current drops.
EN 5012-2 [4] and EN 60077-3 [8] standards do not define permitted arc time $t_{a}$ during critical currents cutting off. Due to safety reasons and maintaining HSCB durability, there has been introduced a provision into the Polish law stating that critical current is defined as the value of current for which the arc time does not exceed $500 \mathrm{~ms}[16]$.

The value and time of critical currents' cutting off depends on HSCB construction, in particular on blowout system. Fig. 6 shows the process of critical current cutting off by HSCB equipped only with blowout coil. After equipping this breaker with an additional blowout system [11] (Fig.7) the critical current value decreased about 10 times.

Many HSCB types are bipolar. It means that they can provide switching operation in both current directions. However, the HSCB construction is not symmetrical, consequently the blowout system interaction is not identical for both current directions.

This phenomenon is particularly visible during critical currents breaking. Fig. 8 and 9 show flows recorded during critical currents breaking by the same breaker for both polarizations - forward (the top terminal $(+)$ is connected from the power supply side) and reverse.

Tests of the above-mentioned HDCB showed that critical current's value is $150 \mathrm{~A}$ for reverse polarization, i.e. three times bigger than for forward polarization.

The knowledge of the phenomena described above is essential in order to select HSCB for particular applications.

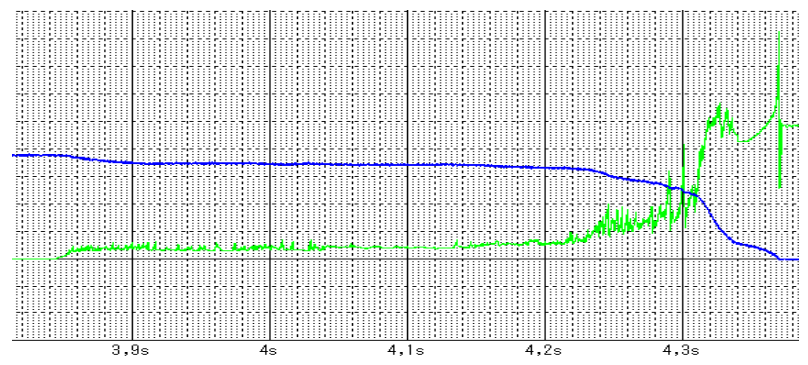

Fig. 6. Critical current cutting off (blue) by HSCB equipped only with blowout coil. $I=250 \mathrm{~A}, t_{a}=535 \mathrm{~ms}$.

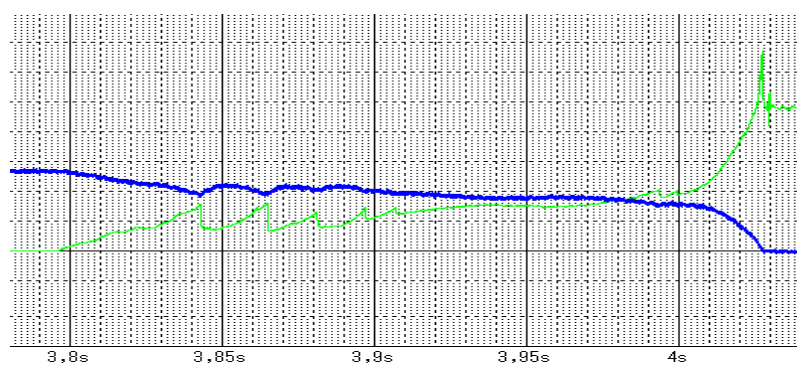

Fig. 7. Critical current cutting off (blue) by HSCB equipped with blowout coil with permanent magnets; $I=25$ A, $t_{a}=231 \mathrm{~ms}$. 


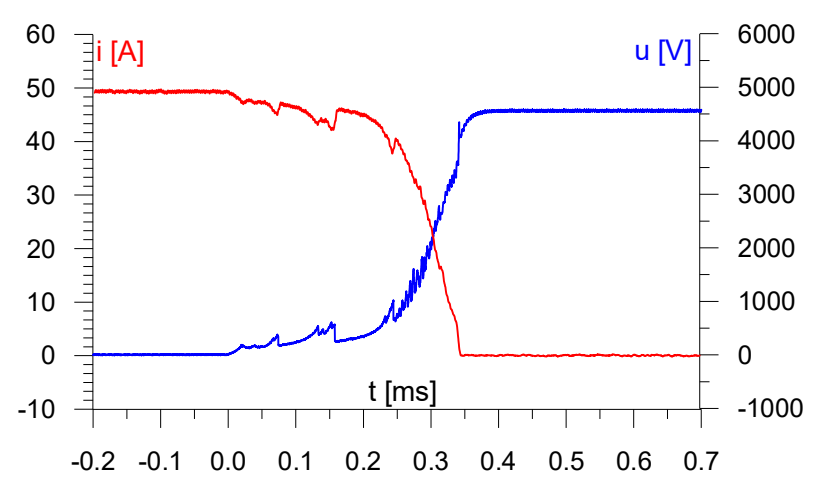

Fig. 8. Current breaking $50 \mathrm{~A}$ - forward polarization; $t_{a}=346 \mathrm{~ms}$

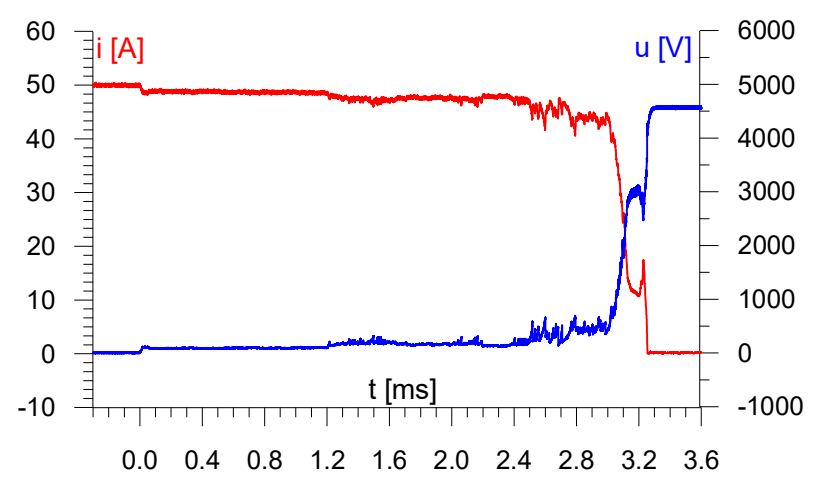

Fig. 9. Current breaking $50 \mathrm{~A}-$ reverse polarization; $t_{a}=3,26 \mathrm{~s}$

\section{Conclusions}

A proper HSCB choice has a profound significance for reliability and safety of the electric traction supply system functioning. Standards regarding HSCB tests contain many general clauses or such ones that create a possibility of test results' different interpretation. Being uncritically directed only by test results, without the knowledge of the tests conditions does not provide an opportunity of choosing a proper HSCB. Importantly, laboratory tests do not allow defining all HSCB parameters that HSCB will show in real traction power supply systems.

Apart from parameters defined in the standards, the knowledge of HSCB construction is vital for their selection as breakers' construction often determines its characteristics.

In order to make requirements, ways of carrying out tests and their results interpretation precise, a standard amendment relating to HSCB would be useful. Until the standards are amended, due to their current provisions, the entities using HSCB should develop detailed requirements, specifying standards as regards expected parameters and methods of their verification.

\section{References}

1. Commission Regulation (EU) No 1301/2014 of 18 November 2014 on the technical specifications for interoperability relating to the 'energy' subsystem of the rail system in the Union.
2. Commission Regulation (EU) No 1302/2014 of 18 November 2014 concerning a technical specification for interoperability relating to the 'rolling stock locomotives and passenger rolling stock' subsystem of the rail system in the European Union.

3. EN 50123-1:2003. Railway applications. Fixed installations. D.C. switchgear. Part 1: General.

4. EN 50123-2:2003. Railway applications. Fixed installations. D.C. switchgear. Part 2: D.C. circuit breakers.

5. EN 50388:2012. Railway Applications - Power supply and rolling stock - Technical criteria for the coordination between power supply (substation) and rolling stock to achieve interoperability.

6. EN 60077-1:2002. Railway applications - Electric equipment for rolling stock. Part 1: General service condition and general rules.

7. EN 60077-2:2002. Railway applications - Electric equipment for rolling stock. Part 2: Electrotechnical components - General rules.

8. EN 60077-3:2002. Railway applications - Electric equipment for rolling stock. Part 3: Electrotechnical components - Rules for D.C. circuit-breakers.

9. S. Klemba, Reliability factor in passenger transport modelling. Railway Reports, 165, 53 - 62 (2014).

10. L. Mierzejewski, A. Szeląg, Research of short circuits and overvoltages in DC electric traction circuits with single-stage transformations $110 / 3 \mathrm{kV}$. $I^{\text {th }}$ International Conference MET'99, 58 - 64 (1999).

11. Ch. Nazeri, Electromechanical Circuit Breaker. Patent US 8513558, (2013).

12. A. Rojek, Switching-off time of electromagnetic blow-out high-speed DC circuit breaker. Railway Reports, 169, 53 - 60 (2015).

13. A. Rojek, M. Sidorowicz. Researches and tests of high-speed circuit breakers for rolling stock and substations in $3 \mathrm{kV} \mathrm{DC}$ traction power system. Railway Reports, 159, 7 - 26 (2013).

14. Type Test Report No. 04157-16-0324. IPH Berlin. Berlin, 14 June 2016.

15. F. Wójcik, F. Theoretical analysis of possibilities for improvement in the effective operation of DC magnetic blow-out circuit breakers. Electrical Review, 5/2011, 186 - 192 (2011).

16. List of the President of the Office of Rail Transport on the relevant national technical specifications and standardization documents, whose application makes it possible to meet the essential requirements for the interoperability of the railway system (Warsaw, 19 January 2017) 